\title{
Quantitative spray analysis of diesel fuel and its emulsions using digital image processing
}

\author{
Ahmad Muneer El-Deen Faik ${ }^{1,2, a}$, Yang Zhang ${ }^{1}$ \\ ${ }^{1}$ Department of Mechanical Engineering, Sir Frederick Mappin Building, University of Sheffield, Sheffield, S1 3JD, UK \\ ${ }^{2}$ Department of Mechanical Engineering, Al-Mustansiryah University, Baghdad, Iraq
}

\begin{abstract}
In the present work, an experimental investigation of spray atomization of different liquids has been carried out. An air-assist atomizer operating at low injection pressures valued (4 and 6 bar) has been used to generate sprays of (diesel fuel, 5, 10, and 15\% water-emulsified-diesel), respectively. A Photron-SA4 high speed camera has been used for spray imaging at $2000 \mathrm{fps}$. 20 time intervals (from 5 to $100 \mathrm{~ms}$ with $5 \mathrm{~ms}$ time difference) are selected for analysis and comparison. Spray macroscopic characteristics (spray penetration, dispersion, cone angle, axial and dispersion velocities) have been extracted by a proposed technique based on image processing using Matlab, where the maximum and minimum (horizontal and vertical) boundaries of the spray are detected, from which the macroscopic spray characteristics are evaluated. The maximum error of this technique is ( $1.5 \%$ for diesel spray) and a little bit higher for its emulsions.
\end{abstract}

\section{Introduction}

Atomization is important in combustion, since most of the combustion systems (such as internal combustion engines and industrial furnaces) work on liquid fuels that cannot be used before being atomized. And it is essential in increasing combustion efficiency in such systems because of the high liquid surface to mass ratio generated after atomization, which in turn leads to higher rates of evaporation and mixing, and then combustion [1]. Atomization is defined as the conversion of liquid from its bulky form into a spray of droplets and other physical dispersions of small particles in a gaseous environment. This could take place due to the kinetic energy of the liquid being atomized, or by being in contact with highvelocity gaseous substance, or as a result of an external force. Despite how the sheet is produced, its instability is increased by the surrounding aerodynamic disturbances, causing it to spread out from the nozzle with a decrease in its thickness and perforations that take place and develop toward each other creating threads and ligaments. The collapse of these ligaments with each other leads to the formation of variable size droplets. The size of these droplets is determined by the liquid sheet initial thickness, velocity gradient between the liquid and the surrounding gas, and liquid physical properties (mainly viscosity and surface tension). However, disintegrating the liquids into small drops is not the only objective of the atomization process, but it is important to ensure a uniform, symmetrical spray is released to the surrounding gas [1].

Characterizing atomization and spray formation is possible currently due to the tremendous improvements in instrumentation and measuring techniques. According to these techniques, spray characteristics can be divided into macroscopic characteristics (such as penetration, cone angle, radial dispersion, and axial velocity) and microscopic characteristics (such as droplet diameters and droplet distribution), where almost all the studies related to sprays and liquid atomization are carried out for investigating one or more of these characteristics. These studies examined the effects of heat transfer [2-3], cavity in flow [4-5], acoustic excitation [6-7], liquid and ambient temperatures [8-10], shear in the flow [11], and many other phenomena on those characteristics.

Conversely, different optical techniques have been used for spray investigation. Of these techniques; the Phase Doppler Particle Analyzer (PDPA) which has been used extensively for investigating spray characteristics for different liquids [12-16] and for high-pressure common rail [17] and liquid-liquid coaxial swirl injectors [18-19], in addition to velocity gradients [20-21], and transient atomization [22]. Mie Scattering is another laser technique that has been used by [23-27] to investigate the characteristics of sprays generated by flash-boiling, pneumatic atomization, slit, piezo-electric, and port fuel injectors respectively. While Laser Induced Fluorescence (LIF) was used to visualize spray atomization [28-29], in addition to the Nd:YAG laser [14, 21, 30-37] and other

\footnotetext{
${ }^{\text {a }}$ Corresponding author: a.faik@sheffield.ac.uk
} 
laser techniques mentioned in [12, 38-48]. Shadowgraphs are used as well in spray atomization investigations either individually [49-52] or accompanied by another optical technique such as laser-based techniques [25, 28] and high speed camera [53]. However, combining shadowgraphy with other techniques is almost useful, since shadowgraphs detect the flow configuration and the other system spots the allocation of spray droplets accurately [28]. Whilst, high speed imaging has been used by [9, 18, 34, 42, 49, 55] for demonstrating the dynamic characteristics of the resulting sprays. Since it gives the opportunity to investigate particles in the range of 10 and $10,000 \mu \mathrm{m}$ in size. Where, instability and nonuniformity at different circumferential positions in the spray can be clearly detected. Flow patterns and turbulence within the sprays could be well recognized as well.

On the other hand, diesel fuel is of great importance in energy production by combustion, especially in the compression ignition engines, where, diesel fuel is injected into the compressed high temperature air in the form of spray. Therefore, spray characteristics of diesel fuel represent a dominant parameter in combustion efficiency and engine performance. Though, a number of studies have been conducted to investigate and describe these characteristics both macroscopically and microscopically. These studies focused on different parameters affecting spray characteristics of the diesel fuel. Where $[17,37,44,58-59]$ investigated the macroscopic spray structure and spray characteristics of diesel sprays generated by common rail type highpressure injector for the diesel engines. While [60-61] aimed to improve diesel atomization by adding dissolved gases $\left(\mathrm{CO}_{2}\right.$ and $\mathrm{CH}_{4}$ respectively) into the liquid. Whereas [62-63] studied the characteristics of diesel sprays generated by acoustic and electrostatic atomization techniques respectively. Additionally, [14] described an experimental and numerical model on microscopic droplet behaviors and macroscopic atomization characteristics of diesel and bio-diesel fuels under the conditions of air cross-flow.

The effect of emulsifying fuel by water on the spray characteristics of the resulting bi-component product has been studied from different sides, where [54, 64-66] studied the atomization of the emulsions flowing through twin-fluid, swirl, and effervescent atomizers respectively, while [67-68] investigated the secondary atomization of an emulsified fuel.

From the previous discussion, it is obvious that optical diagnoses have been used extensively in spray atomization, where the mentioned techniques and a lot more; contributed on going far in the exploration and understanding of spray atomization and the different associated processes. However, different requirements have to be verified in order to get the full advantage of spray imaging. Of these requirements is the automation of analysis due to the vast amount of images that are obtained for every test. Therefore, efforts are directed towards developing automatic image analysis methods, such as those developed by [69-70].
In this work, the macroscopic characteristics of different liquid sprays generated by an air-assist-atomizer are investigated. This investigation has been carried out using high speed imaging of the flow field, then analyzing the obtained images by digital image processing using Matlab for extracting the required features related to time. The aim of this work is to use image processing tools in Matlab for automatic detection and analysis of the different macroscopic features of liquid fuel spray.

\section{Experimental Setup}

The schematic drawing of the experimental setup is shown in figure 1 . Where an air-assisted spray gun with $(1.3 \mathrm{~mm})$ diameter nozzle used to generate sprays horizontally. This gun is connected to an air compressor (of 8 bar max pressure) with an air valve in the flow line. Compressor pressure values have been set to (4 and 6 bar) for each liquid. A Photron-SA4 camera has been used for imaging during the test. Imaging conditions are: frame rate $(2000 \mathrm{fps})$, resolution $(1024 \times 1024)$, and shutter speed $(1 / \mathrm{s})$. Three light sources have been installed perpendicular to the spray gun axis in the ( $\mathrm{Y}$ and $\mathrm{Z}$ ) directions with a light absorbing dark gray background to capture the spray images. Diesel fuel has been tested in addition to three diesel emulsions of water concentrations (5, 10, and $15 \%$ respectively). The emulsions are prepared in the liquid container immediately just before starting the test to avoid deposition and component separation. For each test, the spray gun trigger is operated just once, and an intermittent spray is produced.

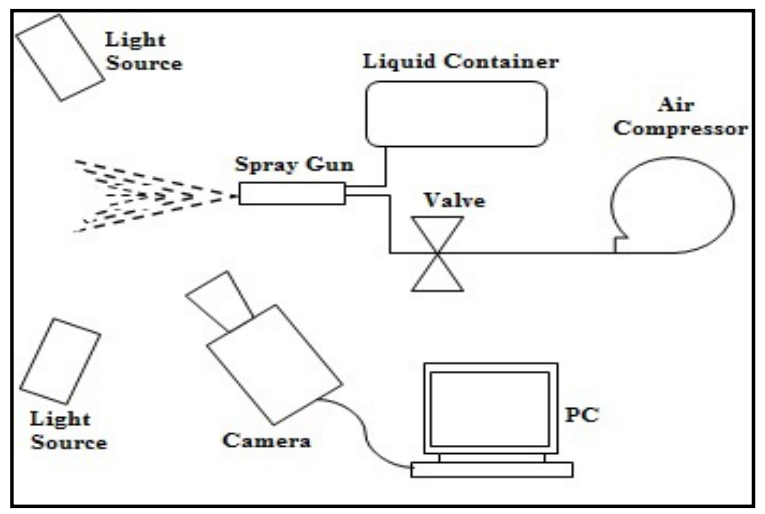

Figure 1: Schematic drawing of the experimental setup.

\section{Results and Discussion}

The images collected from experiments have been processed using Matlab, where an algorithm has been written to read, rename, enhance, and then analyze the selected image (or images) as shown in figure 2. Image analysis starts with binarization, then thresholding, and edge detection. Thereafter, the maximum and minimum boundaries (both horizontally and vertically) are estimated to evaluate spray axial penetration and radial dispersion respectively. 


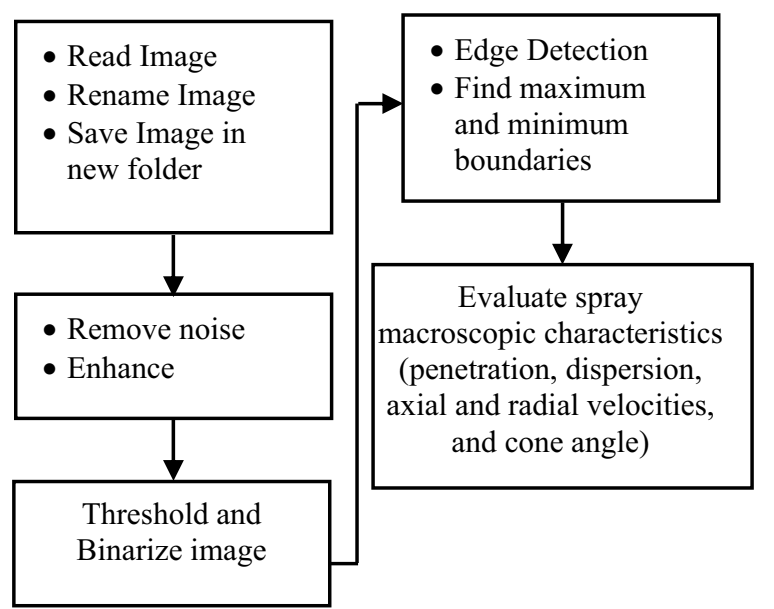

Figure 2: Flowchart of the image processing program.

The suitable value for thresholding has been found by investigating a series of values starting from (10) to (60) marching (10) during the whole period of injection for the two injection pressures and all the liquids under study. Figures 3 and 4 show samples of these threshold comparisons at $25 \mathrm{~ms}$ after injection for the two pressure values.

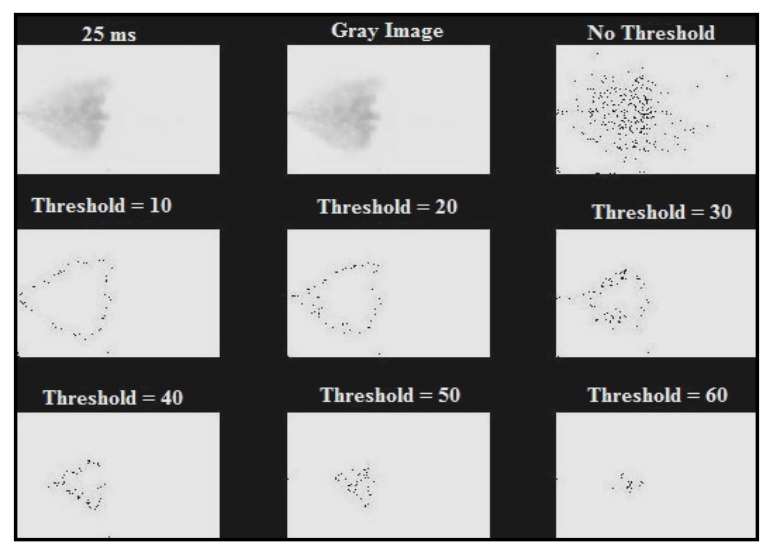

Figure 3: Samples of spray image threshold at 4 bar pressure.

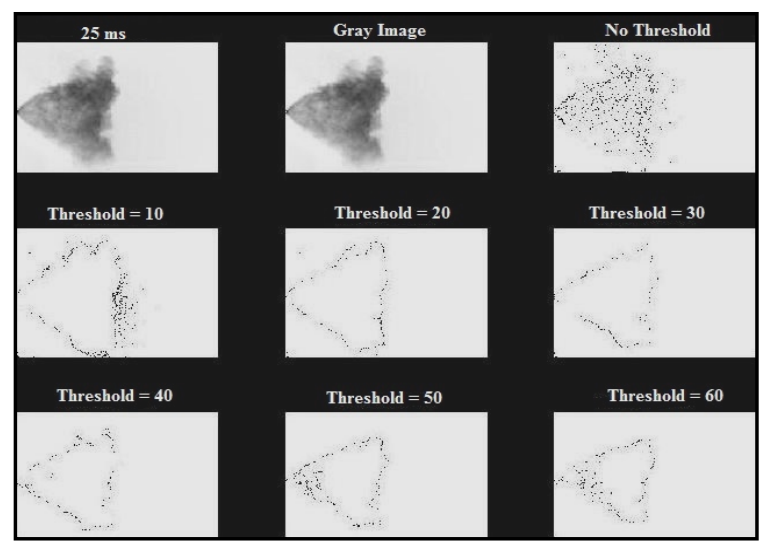

Figure 4: Samples of spray image threshold at 6 bar pressure.

The parameters selected for comparison are the spray projected area and cone angle, where these two parameters are the mostly affected characteristics by changing the threshold value, since they are related to the boundaries of the spray. Therefore, the resulting spray projected area and cone angle have been compared with those corresponding values of the original images and the percentage errors for both pressures have been evaluated and presented in figures 5-8 respectively. From figures 5 and 6 it is shown that the minimum error in the resulting area occurs at thresholds (20 and 30) for the 4 and 6 bar pressures, where the errors at these values for 4 bar are about (1\%) for both diesel fuel and 5\% water-emulsified diesel, $<10 \%$ and $<15 \%$ for $10 \%$ water-emulsified diesel and $15 \%$ water-emulsified diesel respectively. While the errors at 6 bar are almost $<5 \%$ for the 4-liquids at threshold (30).

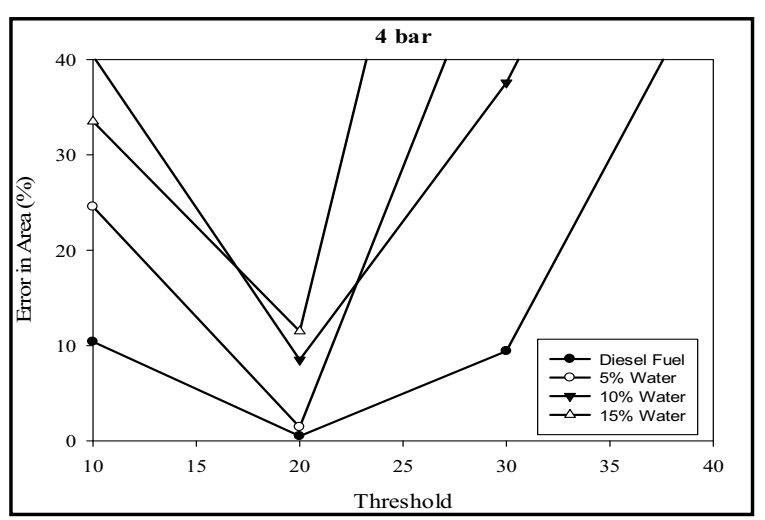

Figure 5: Percentage error in spray area estimation at different thresholds, at 4 bar pressure.

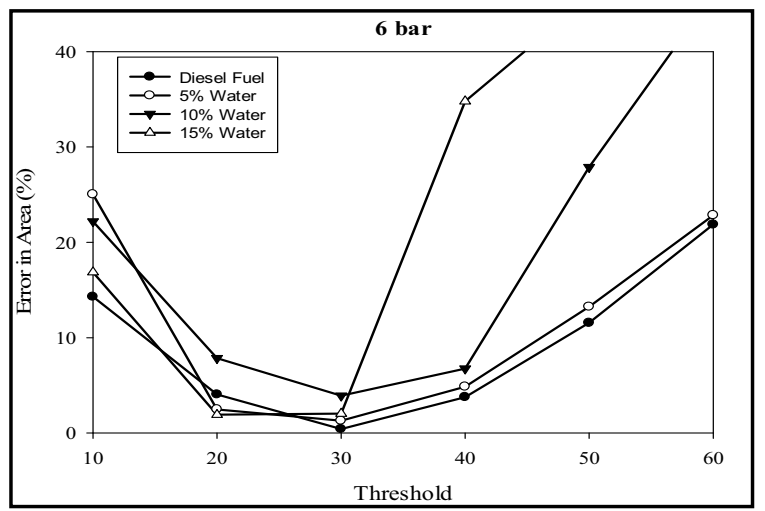

Figure 6: Percentage error in spray area estimation at different thresholds, at 6 bar pressure.

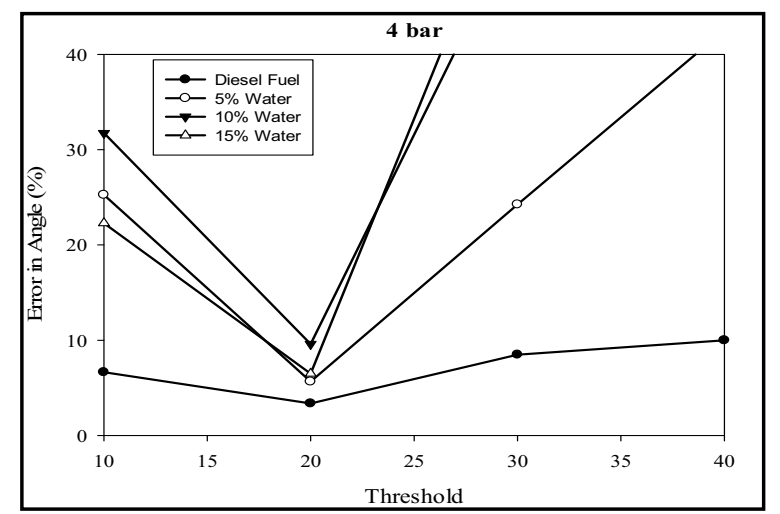

Figure 7: Percentage error in spray cone angle estimation at different thresholds, at 4 bar pressure. 


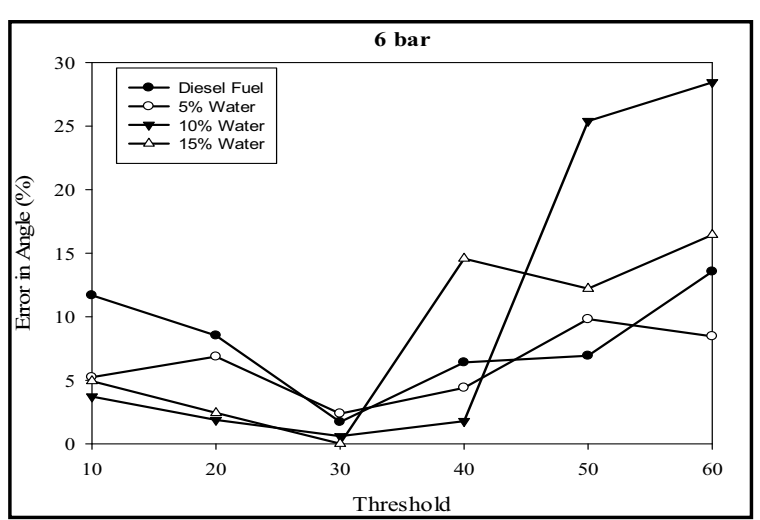

Figure 8: Percentage error in spray cone angle estimation at different thresholds, at 6 bar pressure.

Figures 7 and 8 show exactly the same scenario for errors in cone angle with $<10 \%$ error for almost all liquids at 4 bar and $<5 \%$ for all liquids at 6 bar. Therefore, the thresholds ( 20 and 30 ) have been selected for the analysis of sprays generated by 4 and 6 bar injection pressures respectively.

The analysis incorporated 20 time intervals starting ( 5 $\mathrm{ms})$ to $(100 \mathrm{~ms})$ marching $(5 \mathrm{~ms})$, where the images acquired from the 4-liquids testing under 4 and 6 bar injection pressures have been processed according to the flowchart in figure 2 and the obtained data has been presented in figures 9-19 describing spray penetration, axial velocity, dispersion, radial velocity, and cone angle respectively. In these figures, and for simplicity, the (5, 10 , and $15 \%$ ) water-emulsified diesel fuels will be assigned as $(5 \%$ water, $10 \%$ water, and $15 \%$ water respectively).

Figures 9 and 10 show the increase of penetration of the 4 liquids with time at 4 and 6 bar injection pressures respectively. Form these figures it can be noticed that at early time after injection $(5 \mathrm{~ms})$, injection pressure almost has no effect on the axial penetration of all liquids, in contrast to the other time intervals where it is obvious that increasing injection pressure leads to an increase in spray penetration. It can be noticed as well that the penetrations of the four liquids are almost the same.

Figures 11 and 12 show the decrease of axial velocity of the 4 liquids with time at 4 and 6 bar injection pressures respectively. This velocity is obtained by tracking the difference in traveled distance of the spray on the selected time interval. From the figures, it can be seen that axial velocity is proportional to injection pressure, and that after about (40 ms) after injection, and for a given pressure, all liquids will have almost the same velocity, which means that liquid properties have no dominant effect in controlling spray axial velocity compared to injection pressure. Additionally, it can be noticed that the axial velocity of diesel emulsions are higher than that of pure diesel which could be related to the dynamic viscosity which is higher in the bi-component mixtures than in those single-component base liquids [71]. This is clearly presented in figure 13 which shows the average axial velocity of the 4-liquids at 4 and 6 bar injection pressures. Where, the average velocity of the diesel fuel spray is lower than those of its emulsions at a given pressure.

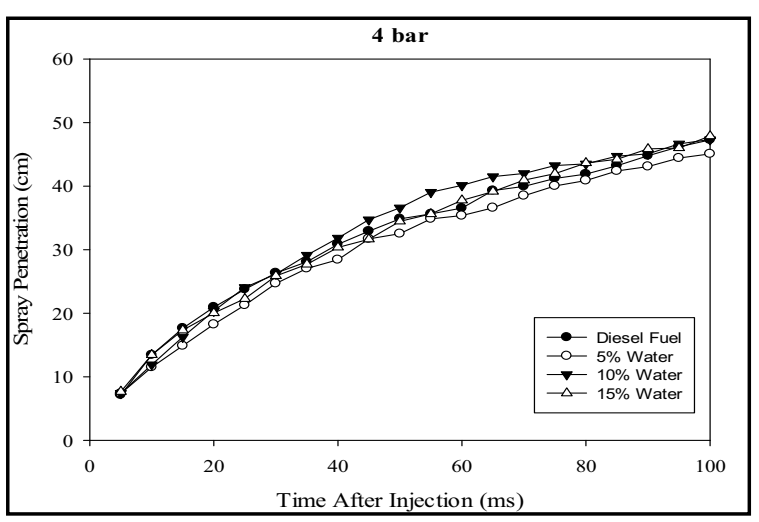

Figure 9: Spray penetration versus time for the 4-liquids at 4 bar injection pressure.

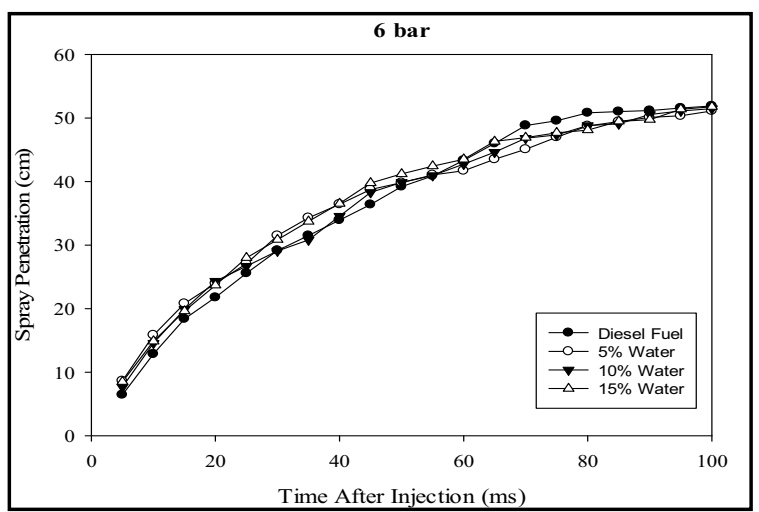

Figure 10: Spray penetration versus time for the 4-liquids at 6 bar injection pressure.

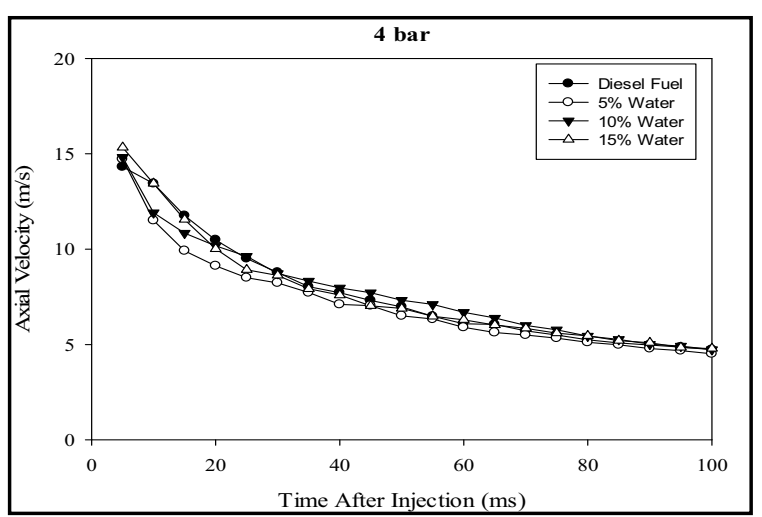

Figure 11: Axial velocity versus time for the 4 -liquids at 4 bar injection pressure.

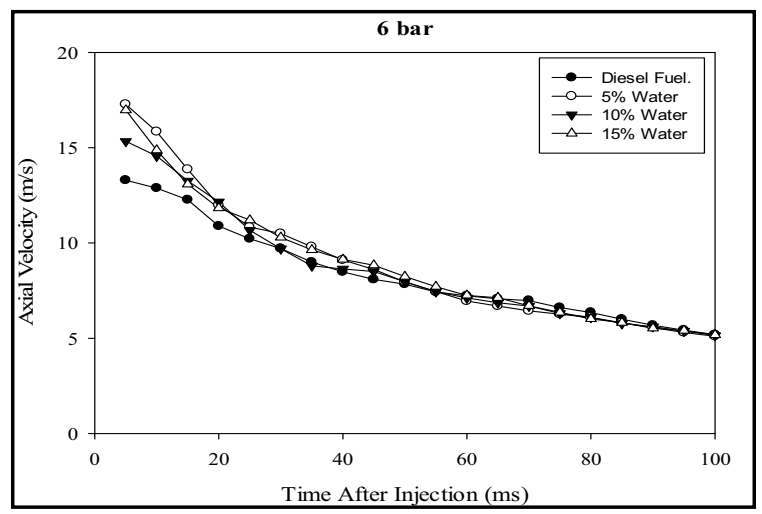

Figure 12: Axial velocity versus time for the 4-liquids at 6 bar injection pressure. 


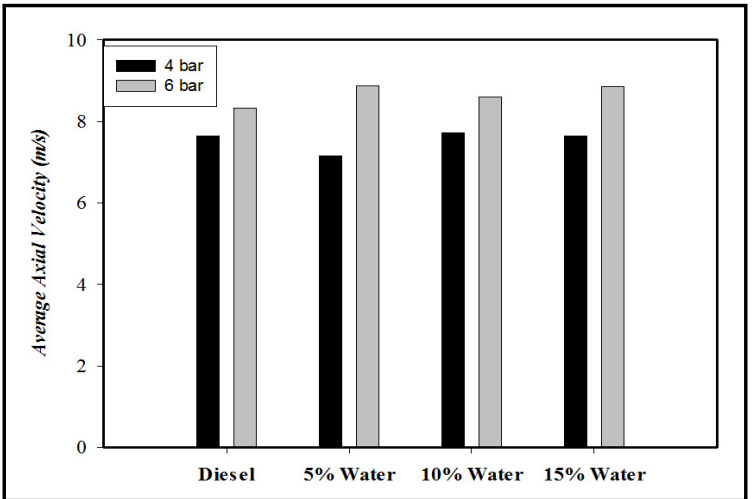

Figure 13: Average axial velocity of the 4-liquids at 4 and 6 bar injection pressures.

Figures 14 and 15 show the dispersion distance of the spray of the 4 liquids with time at 4 and 6 bar injection pressures respectively. Form these figures it can be noticed that at early time after injection $(5 \mathrm{~ms})$, the dispersion distance of all the liquids is almost the same for the two pressures, which is similar to the axial penetration shown in figures 9 and 10 . However, for the later time periods (10-80 ms), it is obvious that injection pressure is effective in increasing dispersion distance, where, the dispersion in 6 bar pressure is almost (1.5-2) times that corresponding distance at 4 bar and the same time. Thereafter, the distances level out for both pressures. It can be noticed as well that all the liquids almost reach their maximum dispersion at the same time at a given pressure, and that this time is inversely proportional with injection pressure $(80$ and $100 \mathrm{~ms})$ for 4 and 6 bar respectively. Additionally, the dispersion of diesel fuel at a given pressure is almost higher than those of its emulsions except the dispersions of the $10 \%$ wateremulsified diesel, as shown in figure 16 that demonstrates the maximum dispersion of the 4-liquids at the 4 and 6 bar pressures. This could be related to the physical properties of the liquids under study, where the surface tension of diesel is lower than those of its emulsions [71], therefore its resistance to rapture is less and its dispersion is higher. Furthermore, by comparing the penetrations and dispersions of the same liquids at the same pressure and instant of time, it can be observed that the dispersion of the liquid is about (1/3) its penetration, and that dispersion is instantaneously irregular compared to penetration.

Figures 17 and 18 show the decrease of dispersion velocity of the 4 liquids with time at 4 and 6 bar injection pressures respectively. This velocity is obtained by tracking the difference in traveled distance of the spray on the selected time interval. From the figures, it can be seen that dispersion velocity is proportional with injection pressure, and that after about $(50 \mathrm{~ms})$ of injection, and for a given pressure, all liquids will have almost the same velocity, which means that liquid properties have no dominant effect in controlling dispersion velocity compared to injection pressure. It can be noticed as well that all liquids almost have the same dispersion velocity with diesel being a little bit the highest in all time intervals. In addition, by comparing the dispersion velocity with the axial velocity in figures
11 and 12 , it can scrutinized that the axial velocity is about $(1.5-2)$ times the dispersion velocity, and that the rate of decrease in axial velocity about twice that of dispersion velocity.

The average spray cone angle of the 4 liquids at 4 and 6 bar injection pressures is shown in figure 19. From this figure, it can be seen that the spray cone angle is proportional with injection pressure, and that it is inversely proportional with water content, where it is the highest in diesel spray and decreases by water emulsion until reaching the lowest values among the four liquids in $15 \%$ water-emulsified diesel. Additionally, it can be inferred that the rate of change cone angle with pressure is inversely proportional with water content as well, where the cone angle of pure diesel fuel increased from $59^{\circ}$ to $74^{\circ}$ by increasing pressure from 4 to $\mathrm{b}$ bar i.e., $15^{\circ}$ of increase compared to $13^{\circ}, 11^{\circ}$, and $10^{\circ}$ of increase for the $5 \%, 10 \%$, and $15 \%$ water emulsified diesels respectively.

From the previous discussions, it can be concluded that the utilized processing technique is beneficial in extracting the macroscopic characteristics of the spray with acceptable errors (almost $<5 \%$ ) within the selected threshold values under certain injection pressures. Therefore, using this technique gives the possibility to estimate spray penetration and dispersion, and then evaluate axial and dispersion velocities and the average cone angle in accordance to the estimated penetration and dispersion values.

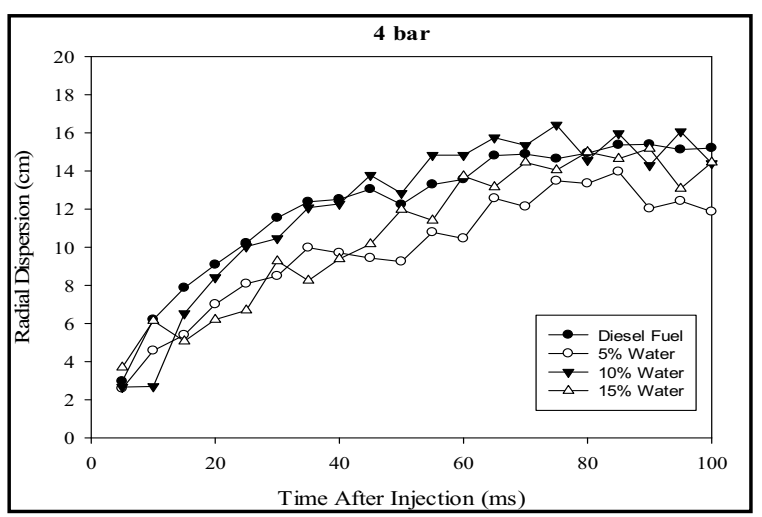

Figure 14: Radial dispersion versus time for the 4-liquids at 4 bar injection pressure.

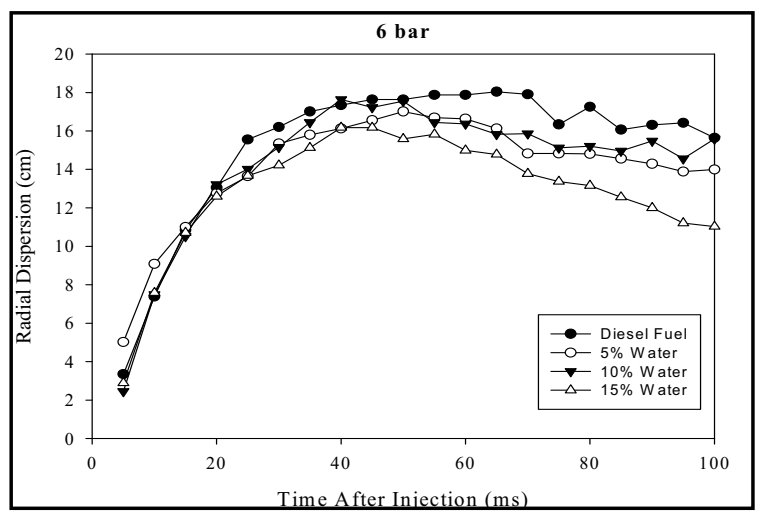

Figure 15: Radial dispersion versus time for the 4-liquids at 6 bar injection pressure. 


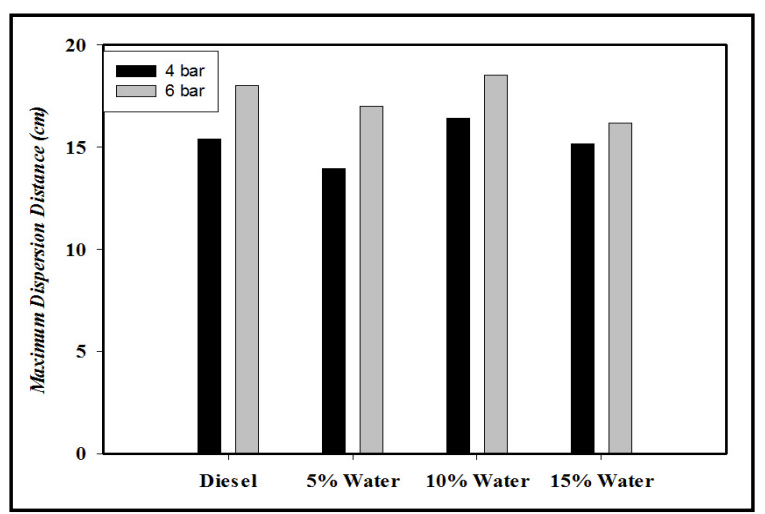

Figure 16: Maximum dispersion distance of the 4-liquids at 4 and 6 bar injection pressures.

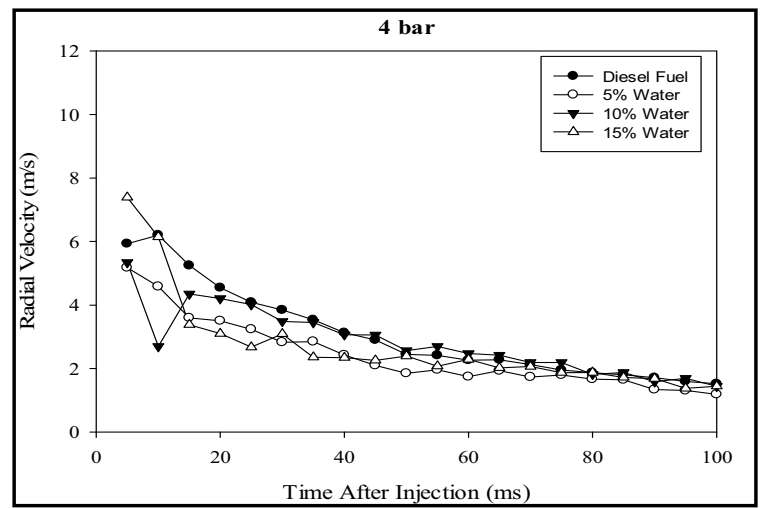

Figure 17: Radial velocity versus time for the 4 -liquids at 4 bar injection pressure.

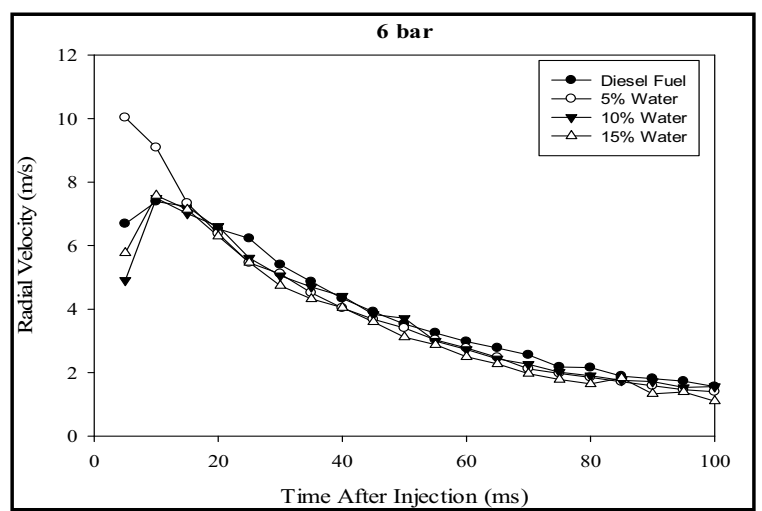

Figure 18: Radial velocity versus time for the 4-liquids at 6 bar injection pressure.

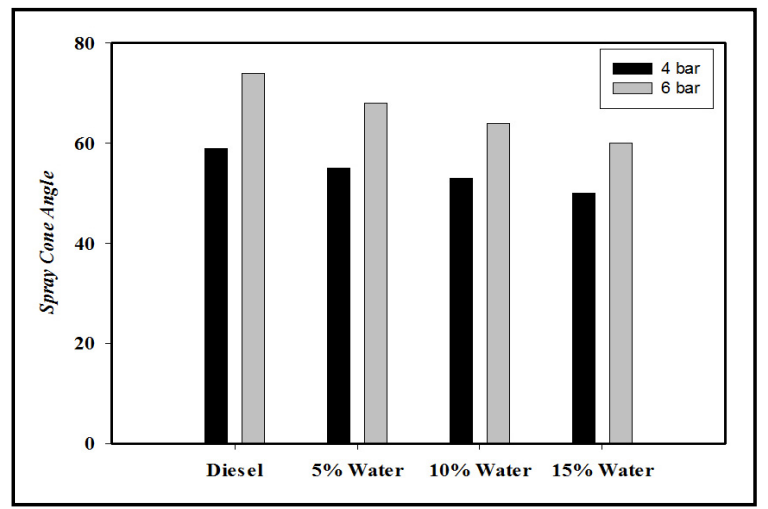

Figure 19: Spray cone angle of the 4-liquids at 4 and 6 bar injection pressures.

\section{Conclusions}

From the previous discussions, the following conclusions can be outlined:

- The utilized processing technique is beneficial in estimating the macroscopic characteristics of the spray with an error below 5\% for most of the cases studied.

- The suitable threshold values for this technique are (20) for sprays at 4 bar injection pressure, and (30) for 6 bar injection pressure.

- Axial and dispersion penetrations are almost the same at the early stages of injection suggesting that at these stages the thermophysical properties of the liquid have no effect on controlling spray characteristics compared to injection pressure.

- The dispersion of diesel fuel at a given pressure is almost higher than those of its emulsions.

- At a given pressure, the axial penetration of the liquid is about (3) times its dispersion at any instant of time.

- The axial velocity of the diesel fuel is less than those of its emulsions, and its dispersion velocity is higher.

- The axial velocity is about (1.5-2) times the dispersion velocity, and the rate of decrease of axial velocity is almost about twice that of dispersion velocity for almost all the liquids under study.

- For a given pressure, the cone angle of diesel fuel is higher than those of its emulsions.

\section{Acknowledgments}

Ahmad M. Faik is grateful to the scholarship awarded by the Higher Committee for Education Development (HCED) in Iraq.

\section{REFERENCES}

1. Lefebvre, A.H. Atomization and Sprays, Hemisphere Publishing Corporation, (1989).

2. Moreira, A. L. N., Moita, A. S., Cossali, E., Marengo, M., Santini, M. Experiments in Fluids, 43(2-3), pp.297-313, (2007)

3. Xie, J. L., Gan, Z. W., Duan, F., Wong, T. N., Yu, S. C. M., Zhao, R. International Journal of Thermal Sciences, 68, pp.94-102, (2013).

4. Park, S. H., Suh, H. K., Lee, C.S. Energy and Fuels, 22(1), pp.605-613, (2008).

5. Suh, H. K., Lee, C.S. International Journal of Heat and Fluid Flow, 29(4), pp.1001-1009, (2008)

6. Basu, S., Saha, A., Kumar, R. International Journal of Heat and Mass Transfer, 59, pp.316-327, (2013).

7. Freret, L., Lacour, C., de Chaisemartin, S., Ducruix, S., Durox, D., Laurent, F., Massot, M. Proceedings of the Combustion Institute, 32(2), pp.2215-2222, (2009).

8. Dombrovskii, L. A., Zalkind, V. I., Zeigarnik, Y. A., Marinichev, D. V., Nizovskii, V. L., Oksman, A. A., Khodakov, K.A. Thermal Engineering, 56(3), pp.191-200, (2009).

9. Park, S. H., Kim, H. J., Lee, C.S. Fuel, 89(10), pp.3001-3011, (2010). 
10. Park, S. H., Kim, H. J., Suh, H. K., Lee, C.S. International Journal of Heat and Fluid Flow, 30(5), pp.960-970, (2009b).

11. Gupta, A. K., Habibzadeh, B. $37^{\text {th }}$ Intersociety Energy Conversion Engineering Conference (IECEC). pp. 269-275, (2002).

12. Aleiferis, P. G., Van Romunde, Z.R. Fuel, 105, pp.143-168, (2013).

13. Deprédurand, V., Castanet, G., Lemoine, F. International Journal of Heat and Mass Transfer, 53(17-18), pp.3495-3502, (2010).

14. Kim, S., Hwang, J. W., Lee, C.S. International Journal of Heat and Fluid Flow, 31(4), pp.667-679, (2010).

15. Kourmatzis, A., Pham, P. X., Masri, A.R. Fuel, 108, pp.758-770, (2013).

16. Park, S. H., Youn, I. M., Lim, Y., Lee, C.S. Fuel Processing Technology, 106, pp.392-401, (2013).

17. Lee, C. S., Park, S.W. Fuel, 81(18), pp.2417-2423, (2002).

18. Engelbert, C., Hardalupas, Y., Whitelaw, J.H. Proceedings of the Mathematical and Physical Sciences. The Royal Society, pp. 189-229, (1995).

19. Soltani, M. R., Ghorbanian, K., Ashjaee, M., Morad, M.R. Aerospace Science and Technology, 9(7), pp.592-604, (2005).

20. Hardalupas, Y., Taylor, A., Whitelaw, J. International Journal of Multiphase Flow, 18(2), pp.159-179, (1992).

21. Park, S. W., Kim, S., Lee, C.S. International Journal of Multiphase Flow, 32(7), pp.807-822, (2006).

22. Kim, D. J., Lee, J.K. International Journal of Automotive Technology, 9(3), pp.297-305, (2008).

23. Matsuoka, H., Sekiguchi, S., Yagi, N., Inoue, K., Ohta, N., Suzuki, T. The Journal of Physical Chemistry C, 113(32), pp.14110-14113, (2009).

24. Moon, S., Bae, C., Choi, J., Abo-Serie, E. Fuel, 86(3), pp.400-409, (2007).

25. Padala, S., Le, M. K., Kook, S., Hawkes, E.R. Applied Thermal Engineering, 52(1), pp.24-37, (2013).

26. Zeng, W., Xu, M., Zhang, G., Zhang, Y., Cleary, D.J. Fuel, 95, pp.287-297, (2012).

27.Zhang, G., Qiao, X., Miao, X., Hong, J., Zheng, J. Fuel, 102, pp.666-673, (2012).

28. Fei, L. S., Xu, S. L., Wang, C. J., Li, Q., Huang, S.H. Science in China Series E: Technological Sciences, 51(2), pp.145-152, (2008).

29. Zigan, L., Schmitz, I., Flügel, A., Wensing, M., Leipertz, A. Fuel, 90(1), pp.348-363, (2011).

30. Anand, T. N. C., Mohan, A. M., Ravikrishna, R. V. Fuel, 102, pp.613-623, (2012).

31. Gao, J., Park, S. W., Wang, Y., Reitz, R. D., Moon, S., Nishida, K. Fuel, 89(12), pp.3758-3772, (2010).

32. Günther, A., Wirth, K.E. International Journal of Heat and Mass Transfer, 64, pp.952-965, (2013).

33. Kim, H. J., Park, S. H., Suh, H. K., Lee, C.S. Energy and Fuels, 23, pp.1734-1742, (2009).

34. Lee, D., You, G., Choi, S., Huh, H. Journal of Visualization, 14(3), pp.273-283, (2011)
35. Park, S. H., Kim, H. J., Suh, H. K., Lee, C.S. International Journal of Heat and Fluid Flow, 30(1), pp.108-116, (2009a).

36. Park, S. W., Kim, H. J., Lee, K. H., Lee, C.S. KSME International Journal, 18(7), pp.1177-1186, (2004).

37. Suh, H. K., Park, S. W., Lee, C.S. Energy and Fuels, 20(4), pp.1471-1481, (2006).

38. Caputo, G., Liparoti, S., Adami, R., Reverchon, E. Industrial and Engineering Chemistry Research, 51(36), pp.11803-11808, (2012).

39. Chen, P., Wang, W., Roberts, W. L., Fang, T. Fuel, 103, pp.850-861, (2013).

40. Gao, J., Nishida, K. Applied Physics B, 101(1-2), pp.433-443, (2010).

41. Godelle, J., Letellier, C., Gouesbet, G. AIP Conference Proceedings, 502, pp.517-523, (2000).

42. Kim, H. J., Park, S. H., Lee, C.S. Fuel Processing Technology, 91(3), pp.354-363, (2010).

43. Pfeifer, C., Bruzzese, C., Fast, G., Kuhn, D., Class, A.G. Flow Measurement and Instrumentation, 22(5), pp.456-460, (2011).

44. Suh, H. K., Park, S. H., Kim, H. J., Lee, C.S. Fuel, 88(6), pp.1070-1077, (2009).

45. Suh, H. K., Park, S. W., Lee, C.S. Proceedings of the Institution of Mechanical Engineers, Part D: Journal of Automobile Engineering, 223(12), pp.1587-1600, (2009).

46. Tsai, S. C., Luu, P., Roski, G., Tsai, C.S. IEEE Ultrasonics Symposium. pp. 715-718, (1998).

47. Yule, A. J., Seng, C. A. H., Felton, P. G., Ungut, A., Chigier, N.A. $18^{\text {th }}$ Symposium (International) on Combustion / The Combustion Institute. pp. 1501 1510, (1981).

48. Yule, A. J., Seng, C. A. H., Felton, P. G., Ungut, A., Chigier, N.A. Combustion and Flame, 44, pp.71-84, (1982).

49. Mayer, W. O. H., Branam, R. Experiments in Fluids, 36(4), pp.528-539, (2004).

50. Milton, B.E., Shock Waves, 16(2), pp.95-107, (2006).

51. Pfeifer, C., Kuhn, D., Class, A.G. Fuel, 104, pp.116-127, (2013).

52. Rahman, M. A., Balzan, M., Heidrick, T., Fleck, B.A. International Journal of Multiphase Flow, 38(1), pp.35-52, (2012).

53. Watanabe, H., Okazaki, K. Proceedings of the Combustion Institute, 34(1), pp.1651-1658, (2013).

54. Ochowiak, M. Chemical Engineering and Processing, 52, pp.92-101, (2012).

55. Park, S. H., Cha, J., Kim, H. J., Lee, C.S. Energy, 39(1), pp.375-387, (2012).

56. Vukasinovic, B., Smith, M. K., Glezer, A. Physics of Fluids, 19(1), p.012104, (2007).

57. Wang, X., Huang, Z., Kuti, O. A., Zhang, W., Nishida, K. International Journal of Heat and Fluid Flow, 31(4), pp.659-666, (2010).

58. Klein-Douwel, R. J. H., Frijters, P. J. M., Somers, L. M. T., de Boer, W. A., Baert, R.S.G. Fuel, 86, pp.1994-2007, (2007).

59. Suh, H. K., Park, S. W., Lee, C.S. Fuel, 86(17-18), pp.2833-2845, (2007). 
60. Xiao, J., Xinqi, Q., Zhen, H., Junhua, F. Chinese Science Bulletin, 49(11), pp.1195 - 1199, (2004).

61. Zhang, J., Jiang, D., Huang, Z., Obokata, T., Shiga, S., Araki, M. Energy and Fuels, 19(5), pp.20502055, (2005).

62. Khandwawala, A. I., Natarajan, R., Gupta, M.C. Fuel, 53, pp.268-273, (1974).

63. Malkawi, G., Yarin, A. L., Mashayek, F. Journal of Applied Physics, 108(6), p.064910, (2010).

64. Broniarz-Press, L., Ochowiak, M., Rozanski, J., Woziwodzki, S. Experimental Thermal and Fluid Science, 33(6), pp.955-962, (2009).

65. Kim, W., Yu, T., Yoon, W. Journal of Mechanical Science and Technology, 26(6), pp.1781-1791, (2012).

66. Schröder, J., Kleinhans, A., Serfert, Y., Drusch, S., Schuchmann, H. P., Gaukel, V. Journal of Food Engineering, 111(2), pp.265-271, (2012).

67. Suzuki, Y., Harada, T., Watanabe, H., Shoji, M., Matsushita, Y., Aoki, H., Miura, T. Proceedings of the Combustion Institute, 33(2), pp.2063-2070, (2011).

68. Watanabe, H., Suzuki, Y., Harada, T., Matsushita, Y., Aoki, H., Miura, T. Energy, 35(2), pp.806-813, (2010).

69. Badreldin, A.M. Computers in Industry, 9(2), pp.107-113, (1987).

70. Saylor, J. R., Jones, B. K., Bliven, L.F. Review of Scientific Instruments, 73(6), pp.2422 - 2427, (2002).

71. Bayvel, L., Orzechowski, Z. Liquid Atomization, Taylor and Francis Publishers, (1993). 